\title{
OPERA BATAK PEREMPUAN DI PINGGIR DANAU KARYA LENA SIMANJUNTAK SEBUAH TINJAUAN SEMIOTIKA
}

\author{
Isna Hidayani ${ }^{*}$, Sahrul $\mathbf{N}^{2^{*}}$, Dharminta Soeryana ${ }^{3^{*}}$ \\ Program Penciptaan dan Pengkajian Seni, Program Pascasarjana \\ Institut Seni Indonesia Padangpajang \\ Jl. Bahder Johan, Guguak Malintang, Padangpanjang, Kota Padangpanjang, Kode Pos 27126 \\ Sumatera Barat. Indonesia \\ Email: titokferry@gmail.com,yusnelli63@gmail.com,freddyhafanis@gmail.com
}

\begin{abstract}
Abstrak
Penelitian ini bertujuan untuk mengungkapkan makna tanda dalam Pertunjukan Opera Batak Perempuan di Pinggir Danau, Penelitian ini menggunakan pendekatan Deskriptif Analisis dengan metode penelitian kualitatif. Kerangka teoritis yang dipilih untuk menjawab pertanyaan penelitian adalah kerangka konsep Semiologi. Beberapa kesimpulan yang dihasilkan dari penelitian ini yakni; Pertunjukan Opera Batak Perempuan di Pinggir Danau memiliki pesan moral yang disampaikan dengan makna yang tersirat pada tanda yang diciptakan oleh Lena selaku Penulis naskah sekaligus sutradara pertunjukan.
\end{abstract}

Kata Kunci: semiologi, perempuan di pinggir danau.

\section{Abstract}

The purpose of the research is to reveal the meaning of sign in Woman at The Lakes Edge Batak Opera Performance. The study used descriptive analysis aproach by quantitative resesrach methode. The theoritical frameworks chosen to answer the research questions are the structural and texture coceptual frammework and the semilogical conceptual framework. Several conclusions resulted from the research are: The Woman at The Lakes Edge Opera Batak Performance has a moral massage that conveyed by the implied meaning of the sign created by Lena as the performance script writer and directure.

Keywords: semiology, woman at the lakes edge.

\section{PENDAHULUAN}

Opera Batak merupakan kesenian kompleks yang terdiri dari beberapa unsur seni, yakni seni tari, seni musik, seni suara, seni drama, dan terkadang juga dihadirkan pencak silat sebagai pertunjukan variatif. Opera Batak adalah jenis pertunjukan teater tradisi lisan yang perkembangannya telah ada sejak tahun 1920, didirikan oleh Tilhang Oberlin Gultom. ${ }^{1}$ Pada tahun 1928, Gultom mengubah nama Tilhang Parhasapi menjadi Tilhang Opera Batak dengan maksud menarik perhatian masyarakat sekaligus sebagai identitas bagi kesenian masyarakat Batak. Kedatangan misionaris-misionaris Jerman dan Belanda yang memperkenalkan agama Kristen dalam kehidupan warga Batak, nyatanya memberikan pengaruh terhadap kesenian Tilhang Opera Batak.Pengaruh tersebut menimbulkan nama baru yang setelah itu diketahui dengan nama Opera Batak.
Opera Batak merupakan bentuk teater yang berangkat dari cerita rakyat. Kisah yang ditampilkan dapat diangkat dari berbagai legenda maupun sejarah kepahlawanan, diantaranya legenda Danau Toba, sejarah pahlawan Sisingamangaraja, dan ada juga yang berangkat dari masalah-masalah kehidupan sehari-hari. Opera Batak Gultom ini belum memiliki teknik penampilan yang teratur sebagaimana lazimnya di dalam drama modern sekarang ini, seperti teknik penyutradaraan, keteraturan plot, perwatakan, tata pentas, kemampuan berakting, dekorasi, tata lampu, tata rias, tata busana, dan tata suara. Oleh karena itu, pertunjukannya dianggap teater tradisi. Jalan cerita disampaikan para pemain melalui dialog-dialog secara improvisasi dan spontan sesuai dengan kemampuan masing- masing pemain/pelaku cerita. Opera Batak Gultom juga memiliki keunikan disetiap garapan, yakni lakon dengan tarian serta nyanyiannya tidak saling 
berhubungan (tidak sinkron) satu sama lainnya. Keberadaannya hanya sebagai pengantar antar babak.

Opera merupakan pementasan sandiwara yang mengisahkan adegan dengan menyanyikan dialogdialog, para pelaku menari dan menyanyikan dialog dengan diiringi musik. Hutari berpandangan Opera adalah sebuah kesenian sandiwara yang dialognya dinyanyikan dengan iringan musik, seperti pernyataannya berikut. "Opera adalah jenis pementasan sandiwara yang pengucapan dialognya dilakukan dengan bernyanyi dan diiringi musik" (Hutari, 2009:7). Opera Batak Perempuan di Pinggir Danau (selanjutnya akan di singkat PdPD) tidak seutuhnya menyerupai keseluruhan garapan Opera dari Eropa namun memiliki beberapa kesamaan, yakni dialog yang dinyanyikan, adanya tarian dan hadirnya musik sebagai pengiring lagu serta sebagai penguat adegan dan peristiwa laku. oleh karena itu, penamaan Opera tetap digunakan pada Opera. hanya saja penyebutnya menjadi Opera bergaya Batak karena lakon umumnya berangkat dari cerita rakyat (foklor) dengan menggunakan bahasa Indonesia diselingi kosa kata Batak.

Naskah PdPD mengisahkan tentang seorang Putri Ikan yang menolak takdirnya menjadi seorang manusia yang diutus ke daratan. Walaupun begitu Putri Ikan tidak bisa lari dari takdirnya karena ketika di dalam kandungan, Ibunya telah berikrar bahwa anak yang dilahirkan akan menjadi putri raja yang ditugaskan untuk menjaga alam. Apabila tidak dijaga, maka keseimbangan yang ada di bumi tidak stabil dan mengakibatkan kerusakan alam. oleh karena itu, ketika Putri Ikan diutus ke daratan Ia menjelma menjadi seorang manusia dan kemudian bertemu dengan seorang petani bernama Samosir. Samosir awalnya tidak mengetahui asal-usul Putri Ikan, namun akhirnya Putri Ikan memberitahu asal-usulnya dengan perjanjian merahasiakan identitas putri tersebut. Salah satu Pertunjukan Opera Batak PdPD karya Simanjuntak (2013) selengkapnya dapat di lihat dari QR Code sebagai berikut:

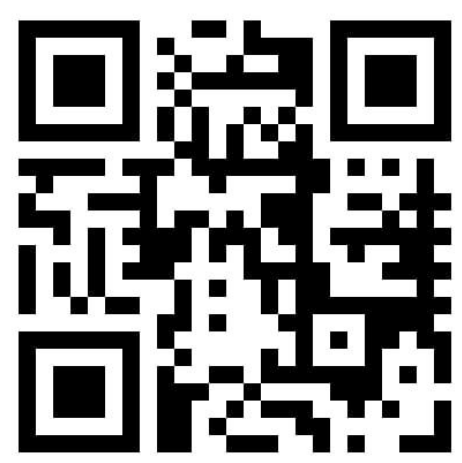

Gambar 1.

QR Code PdPD karya Lena Simanjuntak via Youtube. (Hidayani, 2020)

Penulis naskah PdPD ingin menyampaikan bahwa yang terkena dampak dari pencemaran di Danau Toba adalah masyarakat. Namun yang pertama kali merasakan pencemaran air adalah para perempuan atau ibu-ibu, sebab perempuan yang selalu beraktifitas menggunakan air, baik itu memasak, mencuci, dan memandikan anak-anaknya.

Pertunjukan naskah PdPD ini berdurasi lebih-kurang 1jam 11menit. Naskah PdPD mengambil cerita dari legenda asal muasal terjadinya Danau Toba yang diarahkan oleh dialog (Narator) yang diperankan oleh Thompson Hs. Kisah di atas adalah ringkasan cerita pada naskah PdPD karya Lena Simanjuntak perempuan berdarah Batak Toba yang sekarang bertempat tinggal di Jerman. Lena adalah seorang pendiri Pusat Latihan Opera Batak (PLOt) di Siantar pada tahun 2005. Ia telah memusatkan kegiatannya pada mendukung perempuan terpinggirkan di Indonesia, Teater sebagai media untuk pembentukan dan penguatan penduduk terutama perempuan adalah proyeknya di Papua dan di beberapa daerah terpencil di Indonesia, dengan pekerjaan teater kontemporer Sumatera.

\section{KAJIAN TEORI}

\section{Semiologi Roland Barthes}

Penelitian ini menggunakan pendekatan teori semiologi, yang jelas dan rinci mengurutkan segala bentuk seluk-beluk masalah pemaknaan tanda. Pendekatan Semiologi tersebut dapat dijadikan panduan dalam pembedahan sebuah makna mitos pada daerah dan masyarakat tertentu yang menjadi sebuah tanda atau sebuah identitas budaya masyarakat, khususnya dalam menganalisis sebuah tipe wicara bukan hanya lisan saja tetapi juga tulisan atau representasi ke dalam sebuah pertunjukan teater. 
Semiologi dipilih karena teori ini dapat digunakan untuk menganalisis tanda-tanda yang terdapat pada pertunjukan Opera Batak PdPD untuk mengungkapkan tanda yang terdapat pada pertunjukan PdPD. Barthes berpandangan jika tontonan, protocol, proses ritus, benda-benda, bunyi melodis, gerak tubuh dan gambar bukan merupakan bahasa berarti itu semua sebuah sistem tanda tanpa batasan apapun, Seperti pernyataan berikut:

"Secara prospektif objek semiologi adalah semua sistem tanda, entah apapun subtansinya, apa pun batasannya (limit): gambar, gerak tubuh, bunyi melodis, benda-benda, dan perbagai kompleks yang tersusun oleh subtansi yang bisa ditemukan dalam ritus, protocol, dan tontonan sekurangnya merupakan system signifikasi (pertanda), kalau bukan merupakan 'bahasa' (language)" (Barthes, 2010: 03).

Analisis yang dilakukan pada penelitian ini menggunakan elemen semiologi Barthes Langue (Language) dan Parole (Speech). Langue merupakan sistem bahasa yang bersifat menyeluruh atau umum digunakan dan pemakaiaannya tidak disadari oleh pengguna yang bersangkutan. Sementara parole adalah bahasa yang digunakan oleh pribadi dalam berkomunikasi dengan faktor latar budaya dan sosial. langue jika dianggap memiliki objek studi sistem atau tanda dan kode, maka parole adalah bahasa yang hidup dari individu penggunanya.

Sobur berpandangan langue adalah bentuk sistem dalam sebuah analisis bahasa, sedangkan parole adalah penggunaan bahasa individu dalam berkomunikasi secara sosial dengan maksud menyampaikan makna yang tidak umum, seperti pernyataannya berikut. "analisis bahasa sebagai sebuah sistem adalah langue, dan bahasa sebagaimana ia digunakan secara nyata oleh individu-individu dalam berkomunikasi secara sosial merupakan parole" (Sobur, 2003: vii).

Teori elemen semiologi Roland Barthes dianggap sesuai untuk menganalisis kajian tanda pada pertunjukan Opera Batak PdPD dan diharapkan juga dengan penggunaan teori elemen-elemen semiologi Barthes ini dapat membantu mencari analisis yang terperinci dan akurat kemudian menghasilkan makna tanda pada pertunjukan Opera Batak PdPD.

\section{METODE PENELITIAN}

Mengkai objek penelitian ini peneliti akan menggunakan metode kualitatif sebagai pisau bedah untuk meneliti objek yang diangkat dalam tulisan ini. Denzin dan Lincoln berpandangan penelitian kualitatif
Gorga : Jurnal Seni Rupa

Volume 10 Nomor 02 Juli-Desember 2021 p-ISSN: 2301-5942 | e-ISSN: 2580-2380

tidak hanya mendeskripsikan permukaan suatu objek penelitian tetapi tujuan penelitian untuk lebih memahami mengenai objek yang diteliti lebih dalam. Selanjutnya mereka juga mengatakan bahwa penelitian ini disebut dengan etno-metodologi atau penelitian lapangan, hasil yang didapat dari penelitian kualitatif adalah data-data yang didapatkan di lapangan, seperti pernyataannya berikut:

"Qualitative research is aimed at gaining a deep understanding of a specific organization or event, rather than a surface description of a large sample of a population. It aims to provide an explicit rendering of the structure order, and broad patterns found among a group of participants. It is also called ethnometodology or field research. It generates data about human groups in sosial settings" (Norman, 1994: 4849).

Peneliti menggunakan metode kualitatif, karena dianggap dapat bekerja dalam mengumpulkan data, kemudian menganalisis data yaitu memilih data-data yang didapatkan di lapangan untuk tulisan ini, dan yang terakhir setelah data terpilih lalu peneliti menyimpulkan hasil dari data tersebut dengan rumusan masalah yang diusung dan berdasarkan tujuan penelitian. Sesuai uraian di atas tahapan yang akan ditempuh pada penelitian ini yaitu, Pengumpulan Data (Observasi, Pengumpulan Data Dokumen, Wawancara), Analisis Data, Menyimpulan Hasil Penelitian.

\section{HASIL DAN PEMBAHASAN 1.Hasil}

Ada hal yang dapat diamati dari dialog-dialog dalam pertunjukan PdPD, dimana dialognya memiliki pesan moral yang ditujukan kepada perempuan. Kata-kata yang mempengaruhi langue dan parole terdapat pada kata ikhlas, tanggung jawab dan lemah lembut. Makna yang dimiliki dari sebuah kata tidak selalu tetap karena ada kemungkinan munculnya makna-makna baru dari simbol yang disepakati. Sehingga perempuan yang dianggap lemah akhirnya berubah menjadi perempuan yang tegar dan berani. Hal ini tergambar melalui karakter yang diciptakan penulis pada tokoh Ibu Ikan, dapat terlihat pada gambar berikut: 

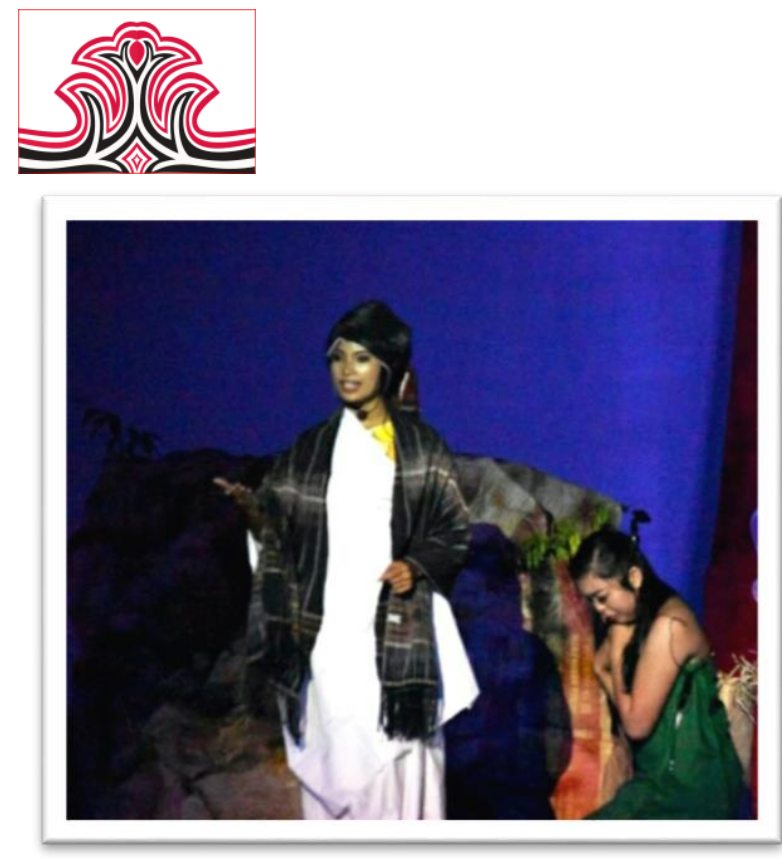

Gambar 2.

Adegan ini Menggambarkan Fisiologis Tokoh Ibu Ikan yang Berada Disebelah Kiri dan Putri Ikan sebelah kanan (Hidayani, 2020)

\section{Pembahasan}

\section{1). Makna Tanda dalam Pertunjukan Perempuan di} Pingir Danau

\section{(1). Langue (Language) dan Parole (Speech)}

Langue merupakan sistem bahasa yang bersifat menyeluruh atau umum digunakan dan pemakaiaannya tidak disadari oleh pengguna yang bersangkutan. Sementara parole adalah bahasa yang digunakan oleh pribadi dalam berkomunikasi dengan faktor latar budaya dan sosial. langue jika dianggap memiliki objek studi sistem atau tanda dan kode, maka parole adalah bahasa yang hidup dari individu penggunanya.

Sobur berpandangan langue adalah bentuk sistem dalam sebuah analisis bahasa, sedangkan parole adalah penggunaan bahasa individu dalam berkomunikasi secara sosial dengan maksud menyampaikan makna yang tidak umum, seperti pernyataannya berikut. "analisis bahasa sebagai sebuah sistem adalah langue, dan bahasa sebagaimana ia digunakan secara nyata oleh individu-individu dalam berkomunikasi secara sosial merupakan parole" (Sobur, 2003: vii).

Berikut peneliti mencoba menganalisa antara tanda atau langue dengan faktor pribadi pengguna bahasa atau parole: 1). Langue: Seorang Putri Ikan yang sudah ditakdirkan untuk menjaga alam air dan daratan. Janji diikrarkan ibunya ketika Ia masih berada dalam rahim yang membuatnya merasa diperlakukan tidak adil karena kodratnya berubah dari tinggal di air kemudian berpindah kedaratan dan tubuhnya juga ikut berubah dari seekor ikan menjadi seorang manusia. Rasa tidak terima dengan kenyataan tidak bisa menjadi penghalang keputusan yang telah ditetapkan dengan
Gorga : Jurnal Seni Rupa

Volume 10 Nomor 02 Juli-Desember 2021

p-ISSN: 2301-5942 | e-ISSN: 2580-2380

rasa sedih Ia tetap menjalankan tugas yang diberikan kepadanya. 2). Parole: Peneliti menemukan dialog, didalamnya terdapat pesan yang ingin disampaikan penulis: Dialog No. 10. 3). 10 Putri Ikan: Tetapi kenapa harus aku? Bukankah bumi, air, tanah dan alam milik semua makhluk? Semua makhluk harus bertanggung jawab menjaganya. Tidak adil kalau ini semua menjadi tanggung jawabku. (Menangis) dan bukankah aku putrimu, kenapa kau jauhkan aku darimu ibu?. Menurut langue perempuan tidak bisa menolak takdir yang telah ditetapkan dan perasaan diperlakukan tidak adil adalah bentuk kelemahan seorang wanita.

Menurut parole kekuatan seorang perempuan justru datang dari rasa ikhlas yang dimiliki untuk menjalankan tugas yang telah di tetapkan. Pemberontakan seorang perempuan adalah ketika perempuan itu berhasil melakukan tugas yang seharusnya bukan menjadi tanggung jawabnya. 4). Langue: Ibu Ikan seorang perempuan kuat dan tegar yang menjadi ciri kesuburan, yang mempunyai itikad melindungi keindahan serta kelestarian air dan tanah. Menurutnya ia diciptakan sebagai perempuan bukan hanya untuk melahirkan dan meneruskan keturunan, tetapi juga menjaga dan merawat lingkungan tempat keturunannya hidup, agar kelak dapat hidup dengan damai, adil dan sejahtera. Ibu ikan merasa kecewa karena apa yang selama ini Ia perjuangkan telah hancur, alam telah mengalami kerusakan akibat tangan manusia rakus yang hanya mengambil keuntungan dari alam tanpa menjaga kelestariannya. Di sini Ibu Ikan mulai memberontak dan menegur para manusia yang telah merusak alam, tetapi Ia dibantah dan ditentang oleh banyak orang karena pendapat banyak orang apa yang mereka lakukan adalah perkembangan dan kemajuan zaman bahkan mengatakan pelestarian alam yang dimaksudkan Ibu Ikan adalah bentuk keprimitifan dan ketinggalan. Akhirnya Ibu Ikan di asingkan dan tidak didengarkan kerusakan alam tetap terus terjadi.

5). Parole: Menurut semiotika Langue Ibu Ikan adalah seorang perempuan yang hanya menjalankan tugasnya sebagai Ibu yang menjaga dan meneruskan keturunan. Perempuan tidak boleh melakukan pemberontakan dan harus memiliki sikap yang lemah lembut. Namun dari kutipan dialog no. 59 dan no.61 ini, peneliti menemukan kekuatan, keberanian dan tanggung jawab besar yang dimiliki seorang perempuan dibalik kodratnya yang harus memiliki sikap lemah lembut. Menurut parole sikap lemah lembut bukanlah bentuk kelemahan dan kepatuhan atas ketidak adilan yang dirasakan perempuan. 6). 59 IBU IKAN: Hai para perempuan, berhentilah merintih dan menangis. Hapus airmatamu, ikat rambutmu, tegakkan kepalamu. Pukul 
genderang, tebarkan senyummu dan nyanyikan dengan nyaring lagu peringatan sambil menyusuri jalan-jalan, lorong dan setiap sudut bumi. Katakan pada setiap orang yang kau temui, kita masih bisa merubah keadaan. 7). 61 IBU IKAN: Kodrat katamu? Harmoni? Puiiih... Perempuan melahirkan itu memang kodrat. Tetapi perempuan harus lembut dan menutup mulut, itu bukan kodrat. Itu adalah pemasungan! Apa maksudmu dengan harmoni? Harmoni itu hanya mitos yang disebarkan untuk menutup mulut dan menutup mata orang-orang demi kepentingan kekuasaan. Bukan katakata hampa tetapi harmoni yang kita butuhkan. Kita butuh saling menghormati. Sumber daya alam harus dimanfaatkan untuk kelangsungan hidup manusia tetapi juga harus memikirkan bagaimana cara melestarikannya terutama air karena yang berperan penting dalam kelangsungan hidup manusia di bumi adalah air. Jika air mulai tercemar manusia akan susah mencari air bersih untuk makan dan minum, manusia juga akan mengalami masalah kesehatan jika mengonsumsi air yang tidak bersih.

\section{KESIMPULAN DAN SARAN}

\section{Kesimpulan}

Bedasarkan penjabaran penelitian tentang makna yang terdapat pada pertunjukan PdPD karya Lena Simanjuntak dikaji menggunakan teori semiologi yang telah di kemukakan. Pertunjukan PdPD disutradarai oleh Lena Simanjuntak memiliki pesan moral tersurat dan tersirat pada tanda yang diciptakan hanya dapat dikaji menggunakan teori Semiologi. Inti dari pesan yang terdapat pada pertunjukan Opera Batak PdPD sebenarnya adalah bagaimana seluruh makhluk dimuka bumi bertanggung jawab dalam melestarikan alam terutama air. Air Danau Toba termasuk sumber daya alam yang harus di jaga kebersihannya oleh masyarakat lokal disekitarnya, dan masyarakat luar yang berkunjung ke sana umumnya. Sesama makhluk penghuni alam kita harus saling menghargai dan menghormati, menjaga kebersihan air termasuk perwujudan dari rasa saling menghormati, karena kita semua hidup memerlukan air.

\section{Saran}

Penelitian yang telah dilakukan diharapkan dapat menjadi masukan bagi kalangan seniman untuk tetap melestarikan Opera Batak sebagai teater tradisional Batak terutama naskah PdPD. Naskah PdPD harus dipentaskan karena naskah ini memiliki pesan-pesan moral untuk penontonya. Kehadiran naskah PdPD ini dapat menjadi pertimbangan bagi semua kalangan baik itu masyarakat umum, seniman dan pemerintahan untuk mengambil kebijakan-kebijakan dalam pelestarian sumber daya alam terutama air.

\section{DAFTAR RUJUKAN}

Barthes, Roland. (2010). Elements Of Semiolog. New York: Hill And Wang.

Hidayani, Isna. (2019). "Opera Batak". Hasil Dokumentasi Pribadi: 28 Juli 2020, ISI Padangpanjang.

Hidayani, Isna. (2020). “Opera Batak”. Hasil Dokumentasi Pribadi: 29 Juli 2020, ISI Padangpanjang.

Hutari, Fandy. (2009). Sandiwara Dan Perang. Yogyakarta: Ombak.

Norman, K. Denzin, Yvonna S. Lincoln. (1994). Handbook Of Qualitative Research. London: Sage Publications Ltd.

Simanjuntak, Lena. (2013). Opera Batak Perempuan Di Pinggir Danau Woman At Lake's Edge Frauen Am Rande Des Sees Borua Nadi Duru Ni Tao. Yogyakarta: Katakita.

Sobur, Alex. (2003). Semiotika Komunikasi. Bandung: PT. Remaja Rosdakarya. 